\title{
Control For HVAC Chilled Water System
}

\author{
Xinrui Yang*, Xiangdong Wang \\ *School of Information Science and Engineering, Shenyang University of Technology, Shenyang 110870, China
}

Key words: chilled water, variable flow, fuzzy control

\begin{abstract}
Based on the principle of conservation of energy, a dynamic heat transfer model is developed. a two-dimensional fuzzy controller is designed to control chilled water flow and chilled water inlet temperature after analyzing the model, so as to achieve the purpose of adjusting the supply air temperature. To verify the feasibility of the proposed method, simulation experiments is made by using MATLAB FIS editor. The results of simulation show that the designed controller can effectively adjust the cooling coil supply air temperature with a small steady-state error, and have the ability of anti-interference.
\end{abstract}

\section{Introdution}

Cooling coil is an important interface in the air conditioning system for both wind system and water system, and it is also an important part of AHU. It cools the air through heat exchange between the refrigerant and the air, so its performance can directly affect the performance of the air conditioner. Therefore, the study of cooling coil are put attach great importance both at home and abroad.

Based on the basic principle of thermodynamics and the basic principle of heat and mass transfer, a mathematical model for the dynamic mathematical model of a cooling coil was established by Meng Hua [1]. The experimental results showed that the simulation of the model has high accuracy and reliability. Guang Yujin [2] pointed out that the method of establishing cooling coil model can be divided into two categories, one is the finite temperature difference method and the other is the lumped parameter method. A simple dynamic model of the cooling device is established by using the finite difference method, and the accuracy of the model is demonstrated by experiments. P Naphon S, Wongwise[3] studied the heat transfer characteristics of an annular cooler in wet conditions, established the model, verified its correctness, and showed the influence of air inlet temperature on the air outlet and water temperature. Yao Y[4] established the dynamic heat transfer model of the cooling coil and carried out the heat transfer analysis. Bai Jianbo[5] got the mathematical model of the cooling coil by test method, and the generalized predictive control algorithm is applied to control the air outlet temperature. Zhou Guowei[6] outlined the basic components of the air conditioning water system as well as the commonly used regulation method, and put forward the method of adjusting the end and controlling the whole temperature.
In general, most research at this stage is focusing to establish the model, and the main achievements are designing the cooling device, and improving the efficiency of heat exchanger, but less pay attention to regulating effect of research results. This paper not only establishes the model, but also focuses on the control method in view of the mediation effects of the supply air temperature.

\section{Cooling Coil Modeling}

\subsection{Assumptions}

1 There are two kinds of working conditions in the heat transfer process: (1) The surface temperature of the cooling coil is lower than the air temperature, but higher than the dew point temperature of the air. At this time, the cooling device is in dry condition, and the air is sensible cooled. (2) The surface temperature of the cooling coil is lower than the air dew point temperature. At this time, the cooling device is in wet condition, and the air is desiccant cooled. Because the cooling coil mostly work in wet condition in the actual operation, this paper focuses on the dynamic model of the cooling coil in wet conditions.

2 The dry air and water vapor will be seen as ideal gas, and the fluid density and heat capacity will be regarded as constants.

3 The temperature of the fluid in the pipe is uniform along the radius.

4 The thermal-conduction resistance of liquid membrane and the second evaporation heat transfer is neglected, when there is condensed water on the exterior surface of the cooling coil.

\subsection{Mathematical Model}

Based on the principle of conservation of energy, a dynamic heat transfer model is developed.

Chilled water:

$$
\rho_{w} c_{w} V_{w} \frac{d_{t_{w, o}}}{d_{\tau}}=c_{w} G_{w}\left(t_{w, o}-t_{w, i}\right)+Q_{1}
$$

Air:

$$
\begin{gathered}
Q_{2=} \rho_{\mathrm{a}} c_{\mathrm{a}} V_{\mathrm{a}} \frac{d_{t_{\mathrm{a}, \mathrm{o}}}}{d_{\tau}} \\
Q_{2}=c_{\mathrm{a}} G_{\mathrm{a}}\left(t_{\mathrm{a}, \mathrm{o}}-t_{\mathrm{a}, i}\right)+Q_{\mathrm{q}} \\
Q_{2}=Q_{\mathrm{x}}+Q_{\mathrm{q}}
\end{gathered}
$$

Metal pipe wall:

$$
M_{p} c_{p} \frac{d_{t_{p}}}{d_{\tau}}=-Q_{1}-Q_{2}
$$


Due to the convective heat transfer rate of the pipe-wall with the water is much faster than that with the air(about100:1), the effective metal quality of pipe-wall can be effectively converted to the quality of the chilled water[7].

Equivalent mass:

$$
M^{*}=\rho_{w} c_{w}+M_{p} \frac{c_{p} t_{p}}{H_{w}}
$$

Translate into:

$$
\begin{aligned}
c_{w}\left(\rho_{w} V_{w}+M_{p} \frac{c_{p} t_{p}}{H_{w}}\right) \frac{d_{t_{w, o}}}{d_{\tau}} \\
\quad=c_{w} G_{w}\left(t_{w, o}-t_{w, i}\right) \\
-c_{a} G_{a}\left(t_{a, o}-t_{a, i}\right)-Q_{q}
\end{aligned}
$$

$\mathrm{Q}_{\mathrm{q}}$ is the sensible heat exchange of air, obtained with the arithmetic mean of temperature difference ${ }^{[8,9]}$ :

$$
Q_{q}=A_{a} h_{a}\left(\frac{t_{w, i}+t_{w, o}}{2}-\frac{t_{a, o}+t_{a, i}}{2}\right)
$$

Meaning of physical quantity:

$H$ : enthalpy

$\rho:$ density

$c$ : specific heat capacity

$\mathrm{V}$ : volume

$t:$ temperature

$\tau$ : time

$\mathrm{Q}_{1}$ : heat exchange amount of chilled water

$\mathrm{Q}_{2}$ : total heat of air

$\mathrm{Q}_{\mathrm{q}}$ : Latent heat of air

Meaning of subscript:

$w$ : chilled water

$a:$ air

$p$ : pipe wall

$i$ : inlet of cooling coil

$o$ : outlet of cooling coil

Take $t_{w, o}, t_{a, o}$ as the state variable, $t_{w, i}, G_{w}$ as control variable, and take $t_{\mathrm{a}, \mathrm{o}}$ as Output variable. That is : $x=\left[t_{w, o}, t_{a, o}\right], u=\left[t_{w, i}, G_{w}\right], y=t_{a, o}$, processing formulas as follow:

$$
\begin{gathered}
\frac{d_{t_{w, o}}}{d_{\tau}}=-\frac{A_{a} h_{a}}{2 c_{w}\left(\rho_{w} V_{w}+M_{p} \frac{c_{p} t_{p}}{H_{w}}\right)} t_{w, o} \\
+\frac{A_{a} h_{a}-2 c_{a} G_{a}}{2 c_{w}\left(\rho_{w} V_{w}+M_{p} \frac{c_{p} t_{p}}{H_{w}}\right)} t_{a, o} \\
+\frac{1}{\rho_{w} V_{w}+M_{p} \frac{c_{p} t_{p}}{H_{w}}} t_{w, o} G_{w} \\
-\frac{A_{a} h_{a}}{2\left(\rho_{w} V_{w}+M_{p} \frac{c_{p} t_{p}}{H_{w}}\right)} t_{w, i} \\
+\frac{1}{\rho_{w} V_{w}+M_{p} \frac{c_{p} t_{p}}{H_{w}} t_{w, i} G_{w}} \\
-\frac{2 c_{a} G_{a}-A_{a} h_{a}}{2 c_{w}\left(\rho_{w} V_{w}+M_{p} \frac{c_{p} t_{p}}{H_{w}}\right)} t_{a, i} \\
\frac{d_{t_{a, o}}=\frac{A_{a} h_{a}}{2 \rho_{a} c_{a} V_{a}}}{d_{w, o}+\frac{2 c_{a} G_{a}-A_{a} h_{a}}{2 \rho_{a} c_{a} V_{a}} t_{a, o}} \\
+\frac{A_{a} h_{a}}{2 \rho_{a} c_{a} V_{a}} t_{w, i} \\
-\frac{2 c_{a} G_{a}-A_{a} h_{a}}{2 \rho_{a} c_{a} V_{a}} t_{a, i}
\end{gathered}
$$

That is:

$$
\begin{aligned}
& \dot{x_{1}}=-\frac{A_{a} h_{a}}{2 c_{w}\left(\rho_{w} V_{w}+M_{p} \frac{c_{p} t_{p}}{H_{w}}\right)} x_{1} \\
& +\frac{A_{a} h_{a}-2 c_{a} G_{a}}{2 c_{w}\left(\rho_{w} V_{w}+M_{p} \frac{c_{p} t_{p}}{H_{w}}\right)} x_{2} \\
& +\frac{1}{\rho_{w} V_{w}+M_{p} \frac{c_{p} t_{p}}{H_{w}}} x_{1} u_{2} \\
& -\frac{A_{a} h_{a}}{2\left(\rho_{w} V_{w}+M_{p} \frac{c_{p} t_{p}}{H_{w}}\right)} u_{1} \\
& +\frac{1}{\rho_{w} V_{w}+M_{p} \frac{c_{p} t_{p}}{H_{w}}} u_{1} u_{2} \\
& -\frac{2 c_{a} G_{a}-A_{a} h_{a}}{2 c_{w}\left(\rho_{w} V_{w}+M_{p} \frac{c_{p} t_{p}}{H_{w}}\right)} t_{a, i} \\
& \dot{x_{2}}=\frac{A_{a} h_{a}}{2 \rho_{a} c_{a} V_{a}} x_{1}+\frac{2 c_{a} G_{a}-A_{a} h_{a}}{2 \rho_{a} c_{a} V_{a}} x_{2}+\frac{A_{a} h_{a}}{2 \rho_{a} c_{a} V_{a}} u_{1} \\
& \begin{array}{c}
-\frac{2 c_{a} G_{a}-A_{a} h_{a}}{2 \rho_{a} c_{a} V_{a}} t_{a, i} \\
y=x_{2}
\end{array}
\end{aligned}
$$

\section{Controller Design}

Fuzzy control is a theory of control strategy based on fuzzy language, fuzzy set theory and fuzzy logic inference. It is build on human knowledge and experience, and it does not need to establish accurate mathematical model of the controlled object, so that we can control a complex system with practical experience of human beings. We can get the 
control rules by summarizing the experience knowledge of human beings and expressing them with fuzzy language, and get the fuzzy control algorithm by quantitatively transforming this control rule through fuzzy mathematics. Then the fuzzy control theory is formed. It has strong antiinterference ability and robustness ${ }^{[10]}$.

In view of the nonlinear dynamic model, this paper proposes the method of fuzzy control.

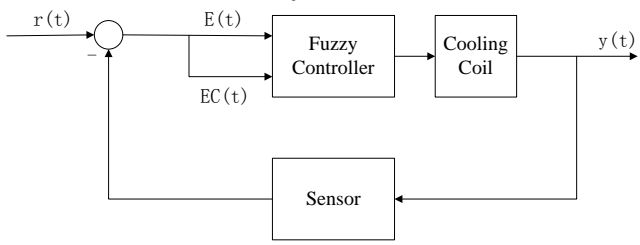

fig.1: Block diagram of the control system.

The two-dimensional fuzzy controller is designed, which takes the error and the error rate as the input variable, and the chilled water inlet temperature and chilled water flow rate as the output variables. The language variable word set of $\mathrm{E}$ and $\mathrm{EC}$ was selected as \{negative big, negative middle, negative small, zero, positive small, positive middle, positive big $\}$, marked as $\{$ NB,NM,NS,Z,PS,PM,PB $\}$. The language variable word set of U1 and U2 was selected as \{ Minimum, very small, small, medium, large, very large, maximum \}, marked as $\{\mathrm{ZX}, \mathrm{CX}, \mathrm{JX}, \mathrm{Z}, \mathrm{JD}, \mathrm{CD}, \mathrm{ZD}\}$. The input domain of the controller is set to $[-20,20]$ and $[-1,1]$, and the output domain is set to $[7,10]$ and $[0,1]$.

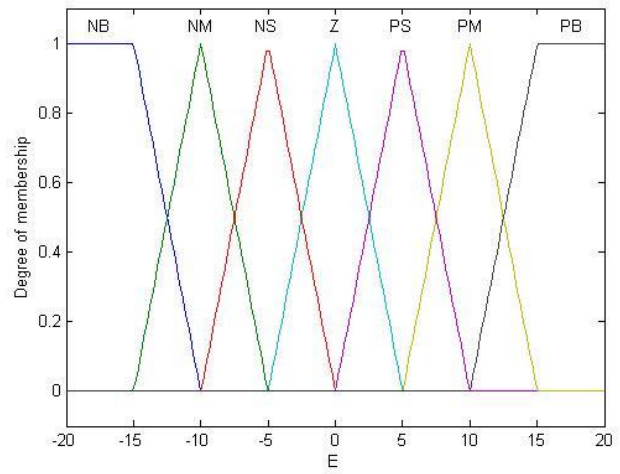

fig.2: Membership function of E.

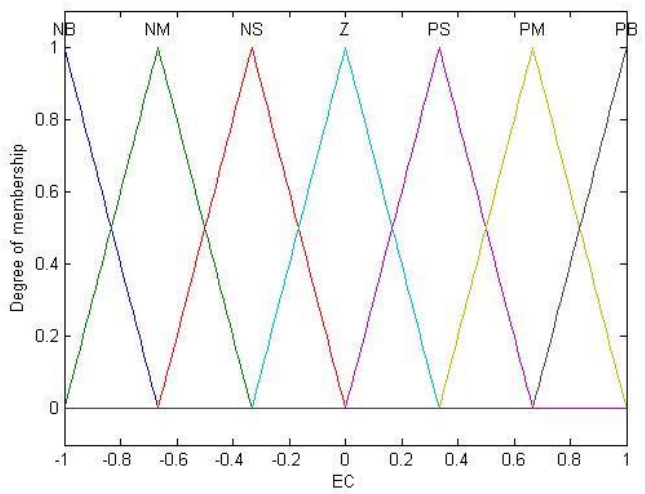

fig.3: Membership function of EC.

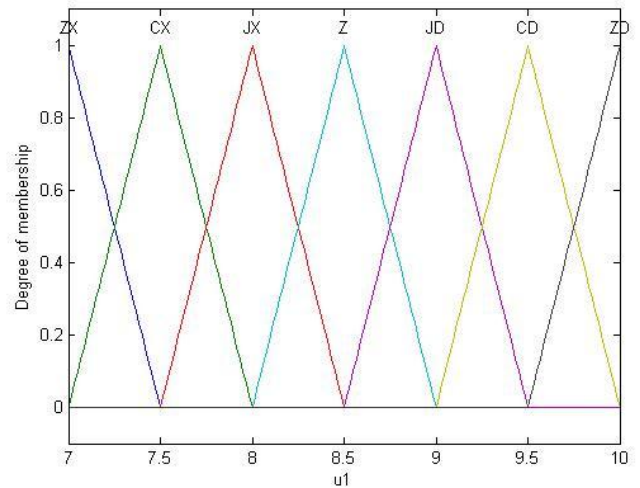

fig.4: Membership function of U1.

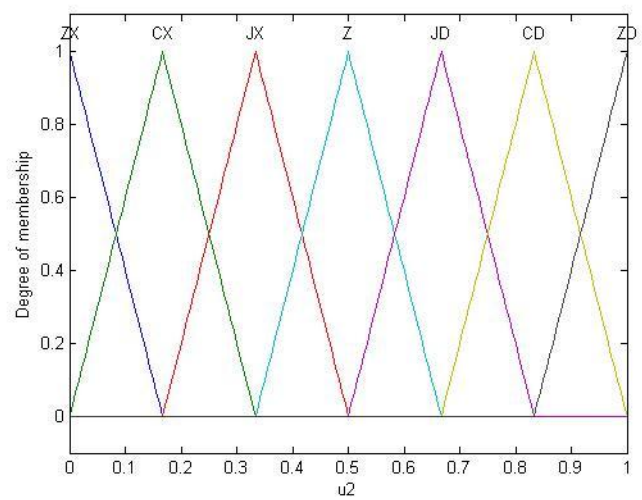

fig.5: Membership function of U2.

The basic idea of fuzzy rules is as follows:

When the error is big negative or middle negative and the error rate is negative, the actual temperature is higher than the set temperature, and the error is increased. In this case, the chilled water flow rate is set to maximum and the chilled water inlet temperature is set to minimum to eliminate the existing errors and restrain the error becomes larger as soon as possible. When the error is big negative and the error is positive, the system has a tendency to reduce the error. In this case, the chilled water flow should take a large amount of control, but not too large, and the chilled water inlet temperature should take a small amount of control but not too small to eliminate the existing errors without overshoot.

When the error is small negative, the system is close to the steady state. If the error rate is negative, the error tends to big negative. In this case, the chilled water flow rate is set to relatively large and the inlet temperature of the water is set to relatively small to restrain the error increasing in the negative direction. If the error rate is positive, the error tends to be eliminated by itself. In this case, the Chilled water flow should not be set to too large, and the water temperature should not be set to too small.

When the error is zero, the actual supply air temperature reaches to the set value exactly, and we just suppress the change of the error. If the error rate is negative, the system error has the tendency to negative direction. In this case, the 
chilled water flow should take a large amount of control, and the chilled water inlet temperature should take a small amount of control. If the error rate is positive, do the opposite.

It can be inferred in the same way when the error is positive.

Table 1. Control Regulation Table of Chilled Water Flow

\begin{tabular}{c|c|c|c|c|c|c|c}
\hline \hline E & & & & & & & \\
EC & & NM & NS & Z & PS & PM & PB \\
\hline NB & ZD & ZD & CD & CD & JD & Z & Z \\
\hline NM & ZD & ZD & CD & CD & JD & Z & Z \\
\hline NS & ZD & ZD & CD & JD & Z & CX & CX \\
\hline Z & ZD & ZD & CD & Z & CX & ZX & ZX \\
\hline PS & CD & CD & Z & JX & CX & ZX & ZX \\
\hline PM & Z & Z & JX & CX & CX & ZX & ZX \\
\hline PB & Z & Z & JX & CX & CX & ZX & ZX \\
\hline \hline
\end{tabular}

Table 2. Control Regulation Table of Chilled Water Inlet Temperature

\begin{tabular}{c|c|c|c|c|c|c|c}
\hline E & & & & & & & \\
EC & & NB & NS & Z & PS & PM & PB \\
\hline NB & ZX & ZX & CX & CX & JX & Z & Z \\
\hline NM & ZX & ZX & CX & CX & JX & Z & Z \\
\hline NS & ZX & ZX & CX & JX & Z & CD & CD \\
\hline Z & ZX & ZX & CX & Z & CD & ZD & ZD \\
\hline PS & CX & CX & Z & JD & CD & ZD & ZD \\
\hline PM & Z & Z & JD & CD & CD & ZD & ZD \\
\hline PB & Z & Z & JD & CD & CD & ZD & ZD \\
\hline \hline
\end{tabular}

\section{Simulation}

To verify the feasibility of the proposed method, simulation experiment taking the HFCF02 type fan coil unit as the object is made by using MATLAB FIS editor. The fuzzy controller uses Mamdani algorithm, and solves the fuzzy by the max-min- barycenter method.

The cooling coil is made of copper material with three rows of pipes, and cold water is used as refrigerant to achieve the purpose of cooling air. The structural parameters and initial working conditions are as follows:

Table 3. Structure Parameter of the Cooling Coil

\begin{tabular}{c|c}
\hline \hline Length/m & 0.47 \\
\hline Radius/m & 0.005 \\
\hline Thickness/m & 0.0005 \\
\hline $\begin{array}{c}\text { Size of air heat exchange } \\
\text { area/m }\end{array}$ & $0.47 * 0.02 * 0.065$ \\
\hline \hline
\end{tabular}

Table 4. Inlet Parameter in Standard Cooling Conditions

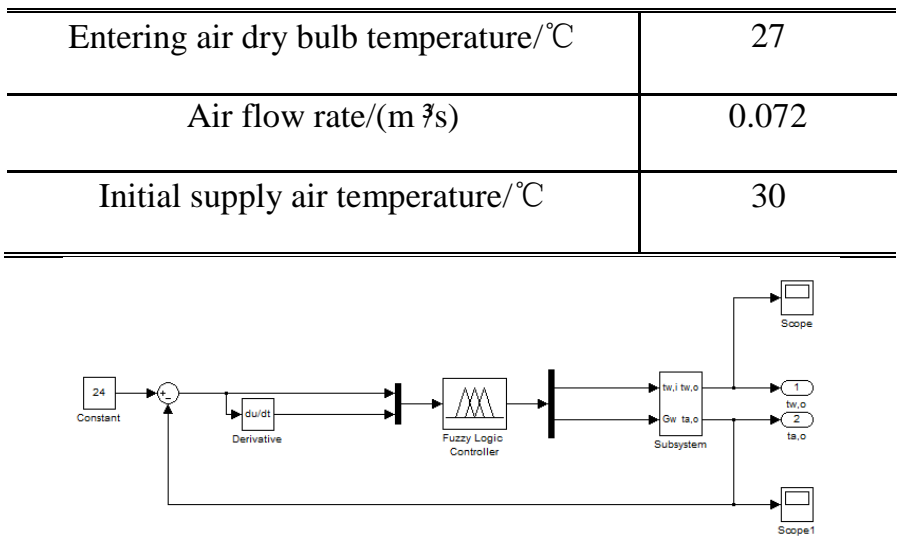

Fig 6: Simulation Block

In order to make the simulation more close to the actual situation, this paper has set up two groups of experiments. In one group, air supply temperature without interference is set to $30^{\circ} \mathrm{C}$. In the other group, air supply temperature with interference is also set to $30^{\circ} \mathrm{C}$.

\subsection{Simulation without Interference}

When the setting temperature is $18^{\circ} \mathrm{C}$, the response speed is fast, the steady-state error is very small, and there is no overshoot.

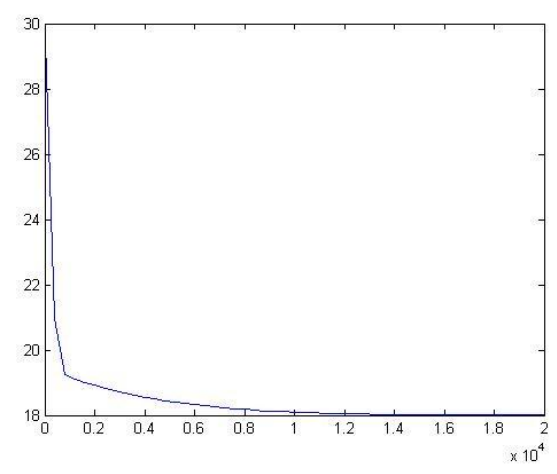

Fig 7: Set Temperature as $18^{\circ} \mathrm{C}$

When the setting temperature is $21{ }^{\circ} \mathrm{C}$, the response speed is fast, and the steady state error is almost zero.

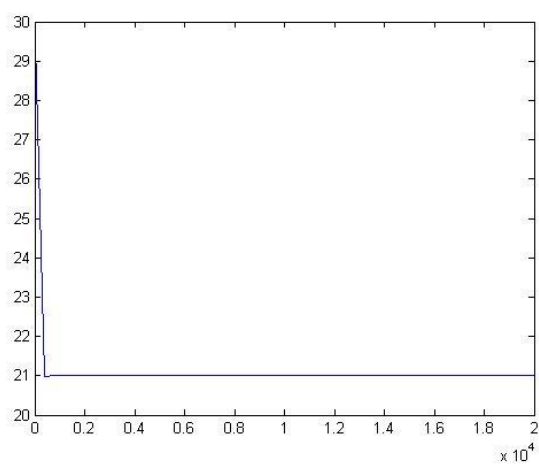

Fig 8: Set Temperature as $21^{\circ} \mathrm{C}$ 
When the setting temperature is $24^{\circ} \mathrm{C}$, there is slight fluctuation, but the response is still into steady state in a relatively short period of time, and the error is small.

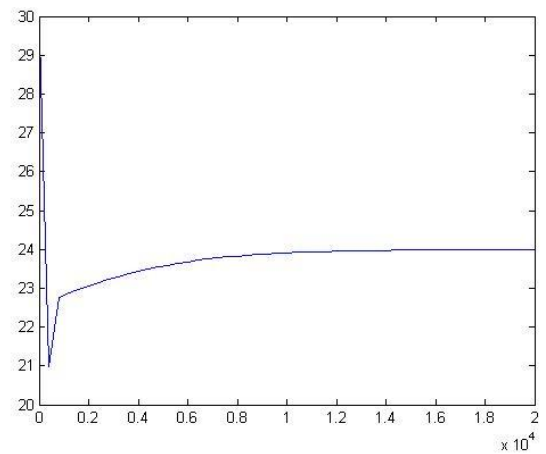

Fig 9: Set Temperature as $24^{\circ} \mathrm{C}$

When the setting temperature is $26^{\circ} \mathrm{C}$, there is also slight fluctuation, and the response goes into steady state in a relatively short period of time with small error.

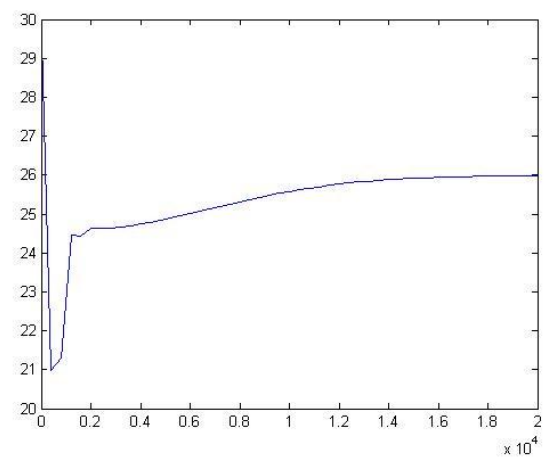

Fig 10: Set Temperature as $26^{\circ} \mathrm{C}$

The results show that when the temperature range is between $18^{\circ} \mathrm{C}$ and $26^{\circ} \mathrm{C}$, the supply air temperature can reach the set value quickly, and the steady-state error is small.

\subsection{Simulation with Interference}

Add an interference of $2^{\circ} \mathrm{C}$ into the supply air temperature when the simulation time is 800 .

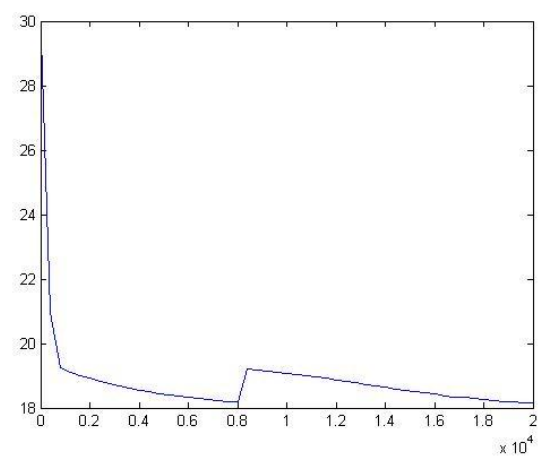

Fig 11: Set Temperature as $18^{\circ} \mathrm{C}$ with Interference

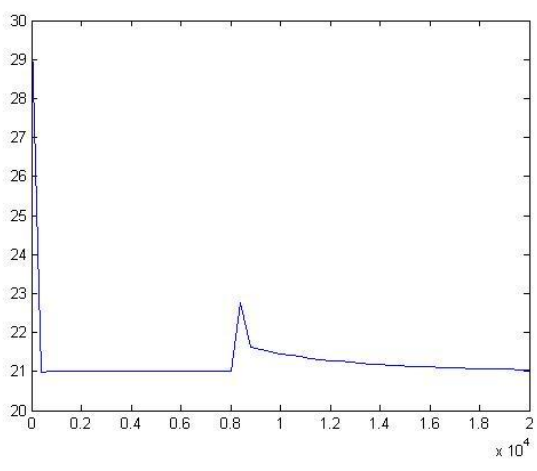

Fig 12: Set Temperature as $21^{\circ} \mathrm{C}$ with Interference

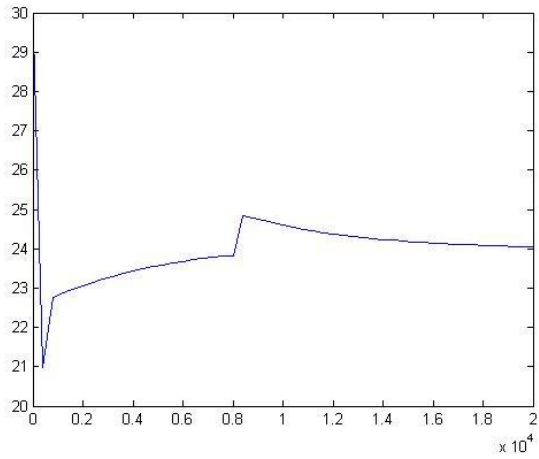

Fig 13: Set Temperature as $24^{\circ} \mathrm{C}$ with Interference

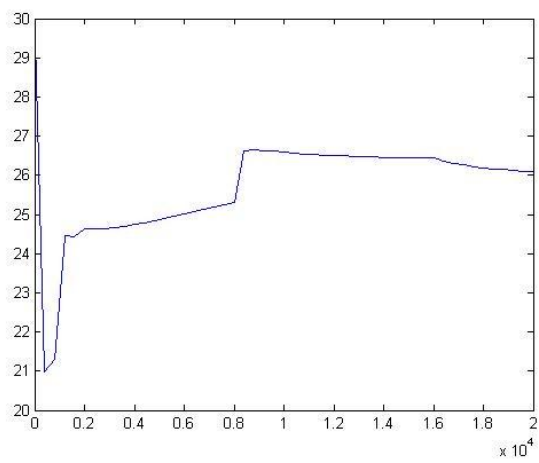

Fig 14: Set Temperature as $26^{\circ} \mathrm{C}$ with Interference

The simulation results show that the controller can make the system return to steady state quickly, and reach the set temperature, which have certain anti-interference ability in the case of interference.

\section{Conclusion}

The heat exchanger model of cooling coil is established and analyzed in this paper. For controlling supply air temperature, the fuzzy controller is designed. Though the simulation experiment with MATLAB, the proposed control method is proved having fast response speed, small steadystate error, and certain anti-interference ability. It can adjust the supply air temperature suitably and adapt to the change of the cooling load of the air-conditioning system, which is conducive to the reduction of the energy consumption. The 
algorithm is not complicated and can be used for real-time control of water system.

\section{References}

[1] Meng hua, Long weiding. "Cooling coil model for system simulation and it's experiment validation", HV\&AC. 34, pp.17-21, (2004).

[2] Guang yujin, Wen jianCai. "A simple dynamic model of cooling coil unit", Energy Conversion and Management. 2915-2930, (2006).

[3] P Naphon S, Wong wise. "A study of the heat transfer characteristics of a compact spiral coil heat exchanger under wet-surface conditions", Experiment Thermal and Fluid Science. 29, pp. 511-521, (2005).

[4] Yao Y. "Thermal analysis of cooling coils based on a dynamic model",Applied Thermal Engineering. 24, pp.1037-1050, (2004).

[5] Bai jianbo, Wang meng. "Control the outlet air temperature of cooling coils based on generalized predictive control", Refrigeration and Air Conditioning.29, pp. 78-82, (2015).

[6] Zhou guowei. Study on fuzzy control for HVAC chilled water systems .Shandong: Shandong university. (2007).

[7] Ni weidou, $\mathrm{Xu}$ xiangdong. Some problems in modeling and control of thermal power systems. Beijing: Science Press. (1996).

[8] Chi guangliang, Zhao tianyi. Dynamic mathematical model and simulation of fin-tube cooling coil s on wet conditions. HV\&AC, 41, pp. 128-133, (2011).

[9] Fan dexi, Lan zhengjie. Mathmatical model and simulation of surface type air coolers. Building Energy and Environment, 28, pp. 22-25, (2009).

[10] Li shiyong. Fuzzy Control. Harbin: Harbin Institute of Technology Press. (2011).

[11] Wang YW, Cai WJ, Soh YC. A simplified modeling of cooling coils for control and optimization of HVAC systems. Energy Conversion Manage. 45, pp. 26592672, (2004). 